\title{
The long-term effects of static stretching at different times of day on hamstring peak torque and flexibility in trained individuals
}

\author{
DOI: https://doi.org/10.5114/pq.2018.734044
}

\author{
Amr Almaz Abdel-Aziem', Amira Hussin Draz², Dalia Mohammed Mosaad² \\ ${ }^{1}$ Department of Biomechanics, Faculty of Physical Therapy, Cairo University, Giza, Egypt \\ 2 Department of Basic Science, Faculty of Physical Therapy, Cairo University, Giza, Egypt
}

Abstract

Introduction. There is some recent evidence that temporal specificity is important for optimizing training for muscular performance. This study was to examine the long-term effects of static stretching performed at different times of day on hamstring torque and flexibility.

Methods. The total of 60 trained male subjects with tight hamstring were selected and randomly divided into 3 equal groups. Group A received static stretch in the morning (07:00-9:00), group B in the afternoon (13:00-16:00), and group C in the evening (18:00-20:00). The hamstring isokinetic concentric and eccentric peak torque and knee extension range of motion were assessed before and after 6 weeks of static stretching (3 repetitions of $30 \mathrm{~s}, 5$ times/week).

Results. A statistically significant increase was observed in hamstring concentric and eccentric torque, and flexibility after static stretching at different times of day $(p<0.05)$. The concentric and eccentric torque post-training values were significantly higher than the pre-training values $(p<0.05)$. The hamstring flexibility post-training values of groups $\mathrm{B}$ and $\mathrm{C}$ were significantly higher than for group $\mathrm{A}(p<0.05)$. The torque and flexibility change scores of groups $\mathrm{B}$ and $\mathrm{C}$ were significantly higher than for group $\mathrm{A}(p<0.05)$, without any significant difference between groups $\mathrm{B}$ and $\mathrm{C}(p>0.05)$.

Conclusions. Afternoon and evening static stretching is more effective than morning stretching in improving the hamstring concentric and eccentric torque and flexibility. Therefore, static stretching is a time-dependent task and should be scheduled by clinicians, coaches, and athletes in the afternoon or evening.

Key words: circadian rhythm, flexibility, isokinetic torque

\section{Introduction}

The circadian rhythms of behaviour and biological functions are synchronized with the light-dark cycle through $24 \mathrm{~h}$ of the day [1]. There is a molecular clock in the skeletal muscle, and the temporal specificity is important for optimizing training for muscular performance [2]. Dudek and Meng [3] maintain that it is still too early to understand the influence of the circadian clock on the physiological functions of the musculoskeletal system.

There is a significant influence of circadian rhythm on body temperature, reaction time, self-rated alertness, fatigue, forward (sit-and-reach) flexibility, and right hand grip strength, all peaking between 16:00 $\mathrm{h}$ and 20:00 h. However, the circadian rhythm has an insignificant influence on whole body flexibility as measured by the stand-and-reach test [4]. Besides, the best scores of balance were found at 13:00 $\mathrm{h}$ and 17:00 $\mathrm{h}$ in a male group and in a trained group [5].

Circadian rhythm has been found to affect the athletic performance levels [6]; the physical performance was significantly higher in the afternoon than in the morning [7]. Moreover, Souissi et al. [8] showed circadian fluctuation in sports performance, with morning lowest values and afternoon highest values. It has been reported that the peak strength of lower limbs is increased over the time course of the day $[9,10]$. The peak isometric extension torque has a significant upward shift in the evening relative to the morning [11].
Moreover, athletes should perform knee flexion strengthening exercises training/competitions in the late afternoon or early evening in order to maximize their performance [12]. However, there were no significant differences in peak torque of knee extensors by time of day at different angular velocities [13].

Recently, Ammar et al. [14] have concluded that the currently available studies investigating the circadian rhythms of physiological functions at rest and after physical exercise are limited. Hamstring flexibility increased significantly throughout the day and was the greatest at 18:00 h [15]. Moreover, tendons are more compliant at night [11]. These studies proved the presence of increased muscle compliance at night, and greater flexibility as a consequence.

There are many explanations for the changes in muscle flexibility through the day. The body temperature is maximal in the early evening, facilitating increased energy metabolism and muscle compliance [16], and the production of testosterone peaks in the morning and declines in early evening, causing changes in tendon stiffness [8]. Moreover, the time-of-day changes in flexibility are attributed to anabolic steroid levels [17].

Static stretching is a common technique used by sports medicine specialists to increase muscle length without potential tissue trauma. It takes the muscle to its end range, and then maintains this position for a specified duration until a 'release' or decreased tissue tension is felt [18]. Ichihashi

Correspondence address: Amr Almaz Abdel-Aziem, Department of Biomechanics, Faculty of Physical Therapy, Cairo University,

7 Ahmed Elziat Street, Ben Elsaryat, El Dokki, Giza, Egypt, e-mail: amralmaz@yahoo.com

Received: 01.12 .2017

Accepted: 06.02.2018

Citation: Abdel-Aziem AA, Draz AH, Mosaad DM. The long-term effects of static stretching at different times of day on hamstring peak torque and flexibility in trained individuals. Physiotherapy Quarterly. 2017;25(1):13-20; doi: https://doi.org/10.5114/pq.2018.734044. 
et al. [19] reported that static stretch intervention reduced the hardness of the hamstring muscle components. Moreover, it is effective in increasing the concentric torque and flexibility of hamstring muscles [20], and successful in increasing the concentric and eccentric plantar-flexors torque and flexibility [21]. A recent review of Medeiros and Lima [22] reported that more than half of the studies found positive effects of stretch training on muscle performance. The improvements were observed only in functional tests and isotonic contractions, without affecting isometric contractions. However, more studies are needed to confirm whether flexibility training can positively affect muscle performance.

Although the previous studies examined the circadian rhythm effect on muscle strength and flexibility and found that the muscular performance was better at specific times of day than at others, no research has been conducted to determine the optimum time of day to perform the flexibility training. So, this study aimed to examine the long-term effects of static stretching carried out at different times of day on hamstring torque and flexibility. The authors hypothesized that the hamstring muscle peak torque and flexibility would be different if static stretch training was applied at different times of day.

\section{Subjects and methods}

\section{Subjects}

This was a randomized prospective study. There were 3 experimental groups, with participants randomly assigned to one of them. Hamstring muscle static stretching was applied in the morning, afternoon, or evening. All groups participated in the same hamstring stretching protocol, and thus there was no comparative control group. This study measured the changes in hamstring muscle flexibility and concentric and eccentric peak torque in all groups.

In the study, 75 trained physical therapy male students were initially identified as potential participants; 12 of them did not meet the inclusion criteria. The total of 63 students, whose age ranged from 18 to 25 years, participated in the study. One participant withdrew from each group. The students were recruited by convenience sampling. In order to be recruited, the individuals had to meet the following inclusion criteria: (1) no physical impairments in either lower limb or lower back in the previous year; (2) the right side being dominant (tested side); the dominant leg was determined by pointing the leg with which the person kicked the ball and hopped over obstacles; (3) the tested extremity exhibiting

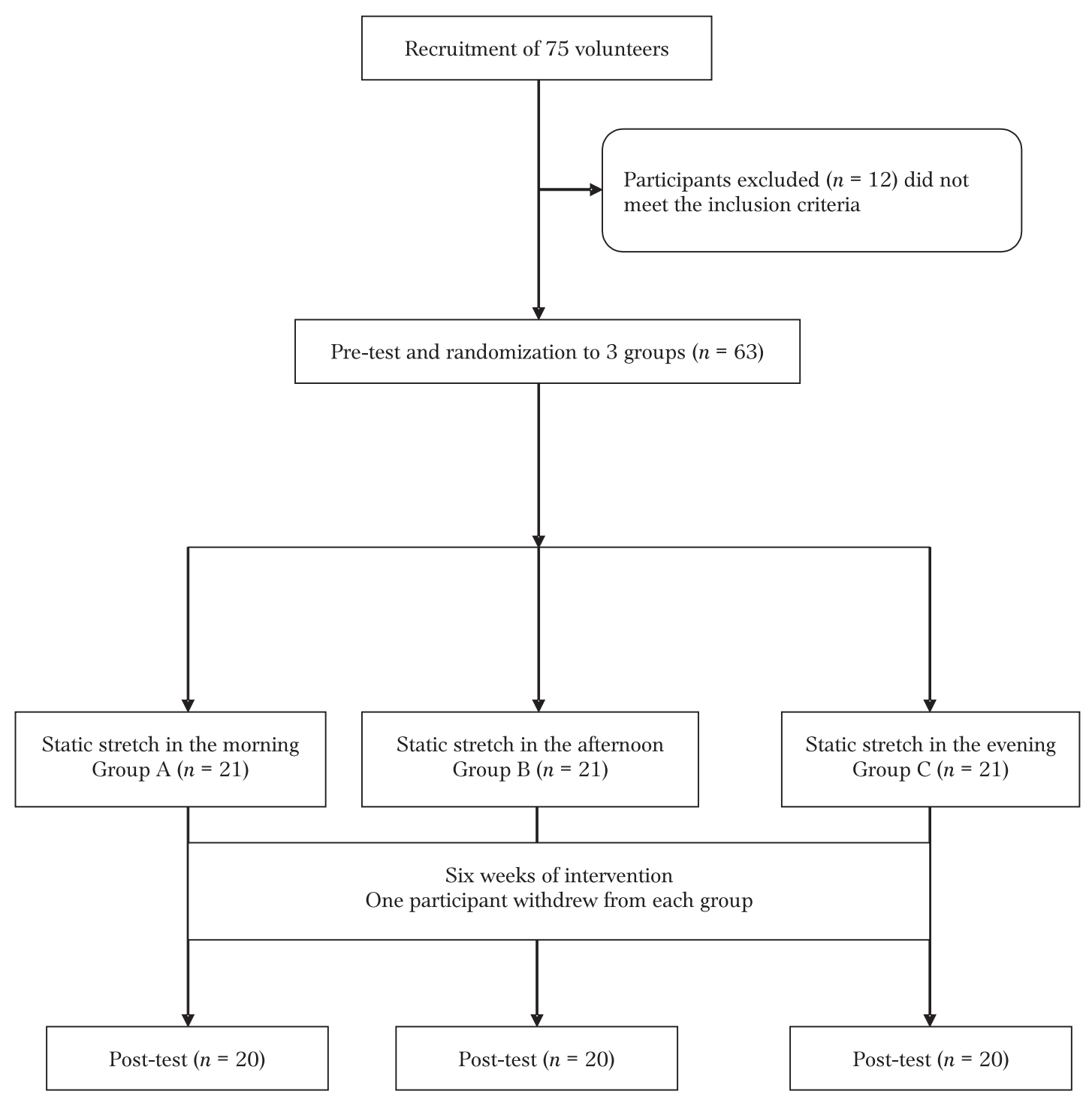

Figure 1. Flowchart showing the study sequence of events 
hamstring tightness with at least $20^{\circ}$ deficit to full knee extension from supine with the hip at $90^{\circ}$; (4) no past history of trauma to the hamstring muscle; (5) no history of neurologic dysfunctions or systemic diseases affecting the lower extremities or ambulation; (6) the participant was considered trained if he had engaged in regular aerobic activity (i.e. running or cycling) at least 3 times weekly for more than 20 minutes a session for more than 6 months [21]. Figure 1 shows the recruitment, assignment, and progression of the participants through the study.

The participants were provided a clear description of the study procedures. They were randomized to 3 groups: the SPSS computer program, version 20.0 (IBM Corp., Armonk, USA) was used to conceal group allocation. Group A received static hamstring stretch training in the morning (07:00-9:00 h). Groups B and C received the same stretch training in the afternoon (13:00-16:00 h) and in the evening (18:00-20:00 h), respectively. The time of intervention was determined in accordance with the study protocol by Deschenes et al. [9] and Sinclair et al. [12]. The participants were randomly assigned after pre-testing. The groups were pre-tested for flexibility and peak eccentric and concentric torque 2 days before starting the stretching programme. Then, the groups began their respective 6-week interventions. The post-testing session was performed 1 week after the intervention end date, at the same time as the training.

The demographic characteristics of the participants are shown in Table 1.

Table 1. Demographic data of the participants

\begin{tabular}{|c|c|c|c|c|}
\cline { 2 - 5 } \multicolumn{1}{c|}{} & $\begin{array}{c}\text { Group A } \\
(n=20)\end{array}$ & $\begin{array}{c}\text { Group B } \\
n=20)\end{array}$ & $\begin{array}{c}\text { Group C } \\
(n=20)\end{array}$ & $p$ value \\
\hline Age (years) & $20.98 \pm 4.20$ & $22.13 \pm 2.27$ & $21.63 \pm 2.41$ & 0.306 \\
\hline Height $(\mathrm{cm})$ & $171.48 \pm 4.20$ & $174.03 \pm 4.63$ & $172.09 \pm 4.20$ & 0.187 \\
\hline Weight $(\mathrm{kg})$ & $66.63 \pm 5.61$ & $68.13 \pm 5.35$ & $69.08 \pm 4.19$ & 0.315 \\
\hline
\end{tabular}

Data are presented as mean \pm standard deviation

\section{Procedures}

All flexibility and strength tests were administered by the same tester before and after the intervention. The pre- and post-training testing procedures were identical. The participants were instructed to wear loose clothing prior to the day of the measurements in order to ensure that the clothing would not provide restriction while measuring the hamstring flexibility and torque.

Knee extension flexibility was tested in accordance with the protocol described by Davis et al. [23]. The subject was instructed to lie on his back with the hips and knees fully extended. A universal goniometer was used to measure the degrees of extension. The axis was placed over the lateral epicondyle of the femur. The stationary arm was positioned parallel to the longitudinal axis of the femur, pointing toward the greater trochanter. The moveable arm was placed parallel to the longitudinal axis of the fibula, pointing toward the lateral malleolus. The leg to be tested was then passively raised by the examiner to $90^{\circ}$ of hip flexion as recorded by another universal goniometer. The axis of this goniometer was placed on the greater trochanter of the femur; the stationary arm was placed parallel to the midaxillary line of the trunk, while the moveable arm was positioned parallel to the longitudinal axis of the femur, pointing toward the lateral epicondyle. The subject's knee was then passively straightened to the point where the subject reported a strong but tolerable stretch in

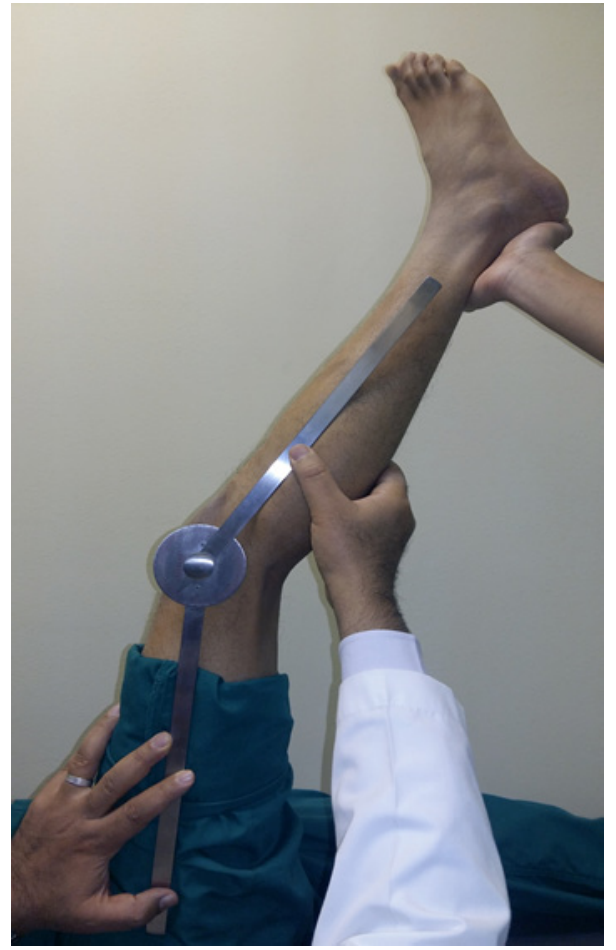

Figure 2. Measurement of knee extension range of motion

his hamstrings. The contralateral lower extremity was fixed to the table in full knee extension with a nylon strap over the distal thigh. The angle of the knee was then measured with the use of the universal goniometer placed on the knee (Figure 2). The goniometer was selected because of its high reliability and common usage by physical therapists in clinical settings [24].

Hamstring torque was assessed with a Biodex dynamometer (Biodex Multi-Joint System 3, Shirley, USA), the room temperature was maintained at $21^{\circ} \mathrm{C}$. Only fruit juice was allowed as breakfast, lunch, or dinner, 90 minutes before the testing session, and only a glass of water $(200 \mathrm{ml})$ was allowed before taking the measurement. The subject warmed up on a stationary bicycle $(75 \mathrm{~W})$ for 5 minutes at the speed of $20 \mathrm{~km} / \mathrm{h}$; this was followed by a set of three 30 -s stretches (with 30-s intervals) focused on knee flexors, knee extensors, and plantar flexors [25]. After that, the subjects were positioned in an isokinetic dynamometer with the backrest reclined $5^{\circ}$ from the vertical plane and knees flexed at $90^{\circ}$. Then, straps were placed across each participant's trunk, pelvis, and thigh to avoid compensatory movements. The dynamometer axis was aligned with the axis of rotation of the knee joint (lateral femoral epicondyle) and the dynamometer lever arm was attached to the distal leg $(5 \mathrm{~cm}$ above the medial malleolus). The familiarization period consisted of 3 submaximal eccentric/concentric contractions of the knee flexors, followed by a 3-minute rest between the warm-up and the actual test, and 1 minute was allowed between the testing speeds of $90 \%$ s. The effect of gravity on torque was corrected with the knee flexed at $60^{\circ}$, and the adjustment for correction was calculated by using the instrument's software [26].

The knee flexor torque was evaluated under eccentric and concentric isokinetic torque at the angular velocity of $90 \%$. The range of motion (ROM) for the eccentric/concentric isokinetic evaluations was set to $70^{\circ}$ (flexion from $90^{\circ}$ to $20^{\circ}$ ). The test consisted of a set of 5 consecutive maximal voluntary eccentric/concentric contractions. The maximum peak torque obtained for the 5 contractions of knee flexors 


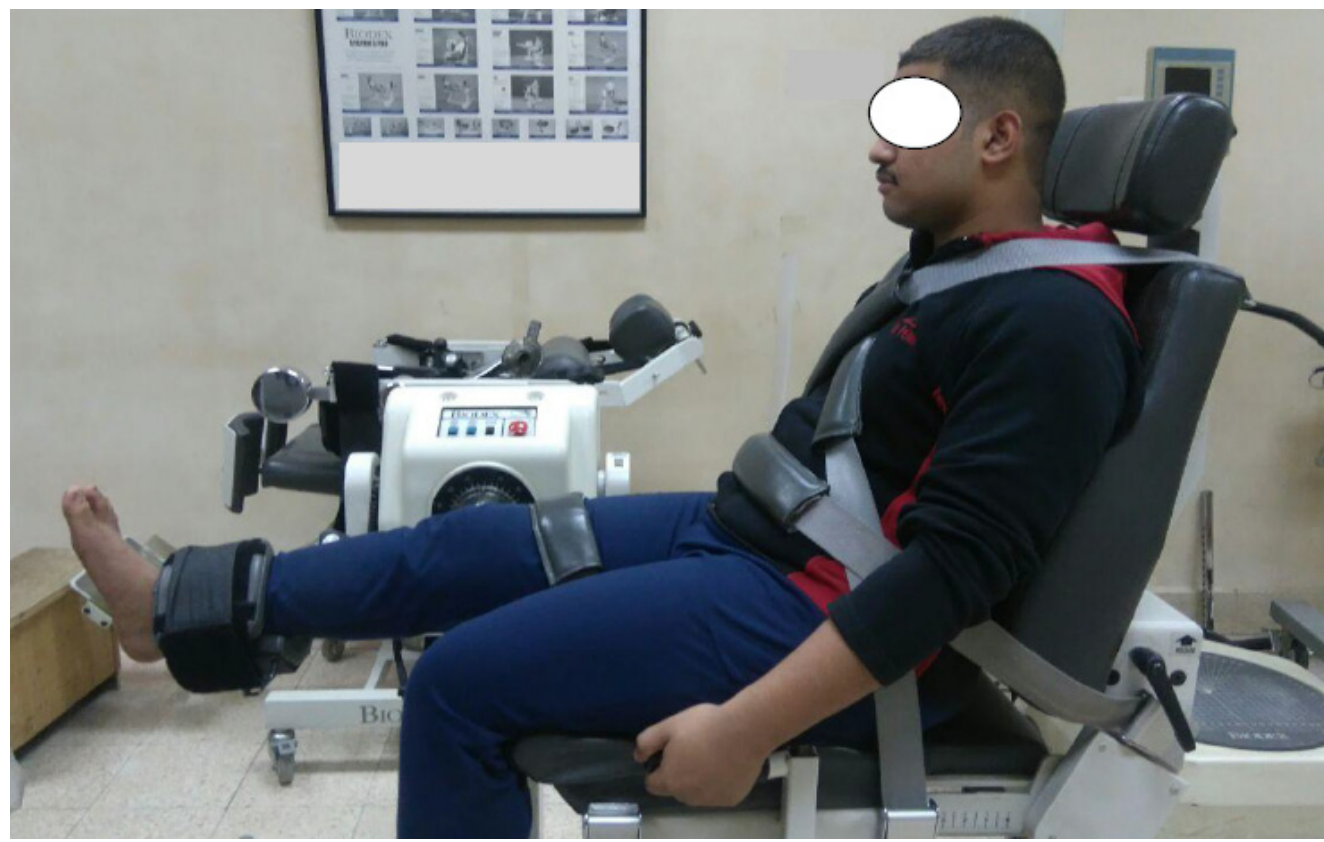

Figure 3. Measurement of hamstring concentric and eccentric torque

was calculated at the end of each set. During evaluation, the subjects received verbal commands from the examiner in a standardized manner to encourage maximal contraction. Additionally, the participants were provided with displayed visual feedback graphs on the instrument's screen (Figure 3).

During static stretching (standing hamstring stretch), the participants stood facing the table of evaluation with the right heel placed on the table edge. Then the subjects were instructed to bend forward and maintain a flat back with the pelvis moved in the direction of anterior rotation. They had to keep a neutral position of the head and the stretched leg in full extension, 3 times for $30 \mathrm{~s}$ each ( 5 days/week). The participants rested for $15 \mathrm{~s}$ between stretches and during the rest period they removed their leg from the table. Warm-up did not occur before the stretching sessions. Also, the subjects wore shorts and removed their shoes for each session. The stretching sessions were supervised by one of the researchers [27]. All individuals received a handout describing the ideal stretch technique and a checklist to keep a record of the days and times they performed the exercises. If a participant missed a stretching session, he stretched later or the next day at the same time of day. Prior to the beginning of the study, it was determined that any subject who missed 2 stretching sessions would be excluded.

\section{Statistical analysis}

Data were analysed with the Statistical Package for Social Sciences, version 20.0 (IBM Corp., Armonk, USA). Descriptive statistics were calculated for the subjects' demographic data. The measured data were analysed and reported as knee extension ROM, and hamstring muscles eccentric and concentric isokinetic peak torques. A one-way analysis of variance (ANOVA) was used to assess the effect of intervention within each group and between groups (pre-training and post-training values) on the dependent variables (concentric torque, eccentric torque, and knee extension). Finally, ANOVA was applied to compare the change scores of the 3 groups. In the case of a significant difference, Tukey's test was performed to identify the source of difference. Statistical significance was set at $p<0.05$ for all tests.
The data were screened for normality assumption, homogeneity of variance, and presence of outliers. This exploration was performed as a pre-requisite for parametric calculations of the analysis of difference. Descriptive analysis with the use of histograms with the normal distribution curve showed that the dependent variables were normally distributed. Additionally, testing for homogeneity revealed that there was no significant difference $(p>0.05)$. Shapiro-Wilk test reflected that the data were normally distributed for all dependent variables. These findings allowed the researchers to conduct parametric analysis.

\section{Ethical approval}

The research related to human use has been complied with all the relevant national regulations and institutional policies, has followed the tenets of the Declaration of Helsinki, and has been approved by the authors' institutional review board (Approval No. P.T.REC/012/001701).

\section{Informed consent}

Informed consent has been obtained from all individuals included in this study.

\section{Results}

There was no significant difference between groups for age, height, or weight ( $p=0.306,0.187,0.315$, respectively), as shown in Table 1. Descriptive statistics of the pre-training and post-training values of peak torque and flexibility in the 3 groups are illustrated in Table 2 .

For hamstring isokinetic concentric torque, there was no significant difference between the pre-training values of the 3 groups $(p=0.572)$. The post-training values of the 3 groups were significantly higher than the values before the intervention ( $p=0.001)$. However, there was no significant difference between the post-training values of the 3 groups $(p=0.200)$. The change scores of groups B and C were significantly higher than that of group A $(p=0.004,0.026$, respectively), without any significant difference between the change score of groups $\mathrm{B}$ and $\mathrm{C}(p=0.478)$.

There was no significant difference between the pre-training 
Table 2. Values of hamstring concentric and eccentric torque and knee extension ROM

\begin{tabular}{|c|c|c|c|c|c|c|c|c|c|}
\hline & \multicolumn{3}{|c|}{ Group A $(n=20)$} & \multicolumn{3}{|c|}{ Group B $(n=20)$} & \multicolumn{3}{|c|}{ Group C $(n=20)$} \\
\hline & $\begin{array}{l}\text { Pre-training } \\
\text { value }\end{array}$ & $\begin{array}{c}\text { Post-training } \\
\text { value }\end{array}$ & $\begin{array}{l}\text { Change } \\
\text { score }\end{array}$ & $\begin{array}{l}\text { Pre-training } \\
\text { value }\end{array}$ & $\begin{array}{c}\text { Post-training } \\
\text { value }\end{array}$ & $\begin{array}{l}\text { Change } \\
\text { score }\end{array}$ & $\begin{array}{l}\text { Pre-training } \\
\text { value }\end{array}$ & $\begin{array}{c}\text { Post-training } \\
\text { value }\end{array}$ & $\begin{array}{l}\text { Change } \\
\text { score }\end{array}$ \\
\hline $\begin{array}{l}\text { Concentric } \\
\text { torque (Nm) }\end{array}$ & $\begin{array}{c}84.20 \pm \\
11.83\end{array}$ & $\begin{array}{c}88.95 \pm \\
12.10^{*}\end{array}$ & $4.75 \pm 2.27$ & $\begin{array}{c}85.90 \pm \\
10.93\end{array}$ & $\begin{array}{c}93.80 \pm \\
11.10^{\star}\end{array}$ & $7.90 \pm 3.57$ & $\begin{array}{l}87.9 \pm \\
10.24^{*}\end{array}$ & $\begin{array}{c}95.05 \pm \\
10.33\end{array}$ & $7.15 \pm 3.99$ \\
\hline $\begin{array}{l}\text { Eccentric } \\
\text { torque }(\mathrm{Nm})\end{array}$ & $\begin{array}{c}99.20 \pm \\
11.39\end{array}$ & $\begin{array}{c}104.65 \pm \\
10.72^{*}\end{array}$ & $5.45 \pm 1.96$ & $\begin{array}{c}100.55 \pm \\
9.75\end{array}$ & $\begin{array}{c}107.6 \pm \\
10.03^{*}\end{array}$ & $7.05 \pm 1.57$ & $\begin{array}{c}101.75 \pm \\
9.60\end{array}$ & $\begin{array}{c}108.90 \pm \\
9.62^{*}\end{array}$ & $7.15 \pm 3.15$ \\
\hline $\begin{array}{l}\text { Hamstring } \\
\text { flexion ROM }\left({ }^{\circ}\right)\end{array}$ & $\begin{array}{c}32.78 \pm \\
4.50\end{array}$ & $\begin{array}{c}26.98 \pm \\
4.93^{*}\end{array}$ & $5.80 \pm 3.76$ & $\begin{array}{c}35.35 \pm \\
4.28\end{array}$ & $\begin{array}{c}23.70 \pm \\
4.17^{*}\end{array}$ & $11.65 \pm 3.67$ & $\begin{array}{c}34.25 \pm \\
3.65\end{array}$ & $\begin{array}{c}24.08 \pm \\
3.54^{*}\end{array}$ & $10.18 \pm 3.29$ \\
\hline
\end{tabular}

Data are presented as mean \pm standard deviation.

ROM - range of motion

* Means significant difference between pre-training and post-training values $(p<0.05)$.

values of hamstring isokinetic eccentric torque of the 3 groups $(p=0.736)$. The post-training values of the 3 groups were significantly higher than the values before the intervention $(p=0.001)$. However, there was no significant difference between the post-training values of the 3 groups $(p=0.403)$. The change scores group $B$ and $C$ were significantly higher than that of group $A$ ( $p=0.034,0.024$, respectively), without any significant difference between the change score of groups B and C ( $p=0.892)$.

Regarding hamstring flexibility, there was no significant difference between the pre-training values of knee ROM between the 3 groups $(p=0.155)$. The post-training values of group $B$ and $C$ were significantly higher than that of group $A$ $(p=0.018,0.035$, respectively). There was a significant improvement in the hamstring flexibility in the 3 groups $(p=0.001)$. The change scores of group $B$ and $C$ were significantly higher than that of group $A(p=0.001)$, without any significant difference between the change score of groups $B$ and $C(p=0.198)$.

\section{Discussion}

The presented study was conducted to examine the longterm effect of applying static stretch at different times of day on hamstring concentric and eccentric peak toque and hamstring flexibility. The hypothesis of the study was accepted as the results proved that the static stretching of hamstring in the afternoon or in evening increased the concentric and eccentric torque and hamstring flexibility more than the stretching in the morning. The current study was the first to divide subjects into morning, afternoon, and evening groups for comparison, on the basis of the assumption that there is enough variability between morning, afternoon, and evening strength and flexibility to affect the overall gains. This assumption may have been too far reaching and leading to the lack of consistent results with the current study. Thus, there was a difficulty to compare the findings of the present study with previous literature on circadian rhythm. All prior studies measured the change in each subject's strength and flexibility over the course of a day.

The significant improvement in the 3 groups is supported by the findings of Hill et al. [28], who demonstrated that there was temporal specificity in training to increase work capacity. The greater improvements occur at the time of day at which high-intensity training is regularly performed. Additionally, the gains of afternoon and evening groups in the current study were significantly higher than those of the morning group, which concurs with some of the previous studies that reported that the physical performance of swimmers [29] and cyclists [30] was gradually increased through the day that was positively correlated with the body temperature. Moreover, West et al. [31] compared the jumping score at 10:00 $\mathrm{h}$ and 17:00 $\mathrm{h}$. They found that the peak power output of jumping was higher at 17:00 h. So, it is concluded that slight circadian rhythm of the body temperatures might affect the physical performance of elite players.

The improvement of hamstring flexibility of the 3 groups is consistent with the findings of Bandy and Irion [32] and the recent study by Cini et al. [33], who reported that a 30-s static stretch was sufficient for increasing the hamstring flexibility. However, Berenbaum et al. [34], who investigated whether 3 weeks of either static or dynamic hamstring stretching affected ROM and anaerobic exercise performance in recreationally active individuals, reported that there were no significant differences between groups for the horizontal jump, vertical jump, or 50-meter sprint. Furthermore, 3 weeks of either static or dynamic hamstring stretching did not improve ROM in the active subjects. This contradiction in the results may be due to the short duration of the applied training program as these studies did determine a certain time for the application of stretching techniques.

The findings of the current study are supported by the results which reported that the hamstring static stretching was effective in increasing the concentric torque of hamstring muscles and raised the knee extension ROM [20]. Likewise, it has been proved that the static stretching of plantar-flexors was effective in increasing the concentric and eccentric plantar flexion torque and improved the plantar-flexors flexibility in untrained and trained subjects [21]. It is worth mentioning that the stretching sessions of these studies were performed randomly between 10:00 $\mathrm{h}$ and 17:00 h, which may have inversely affected the results as the significant physiological differences in the period specified by the authors [4].

The improved flexibility of the afternoon and evening groups as compared with the morning group is supported by the findings of Gifford [35], who showed that the fingertip to floor was stiff at 06:00 h, and the flexibility gradually increased to maximum at midday to midnight. Similarly, lumbar flexion measurements demonstrated the highest stiffness in the morning, with flexibility increasing to the peak in late afternoon and early evening, followed by increased stiffness. Likewise, Guariglia et al. [15] assessed the hamstring length and found that the flexibility increased significantly throughout the day and was greatest at 18:00 h. Furthermore, Pearson and Onambele [11] examined the time-of-day variability of internal muscle structure and infrapatellar tendon characteristics. They concluded that tendons were more compliant at night. These studies proved the presence of increased 
muscle compliance at night, and greater flexibility as a consequence.

The changes in muscle flexibility through the day can be explained by the findings of Teo et al. [16], who reported that the body temperature, being maximal in the early evening, increased the energy metabolism and muscle compliance. In addition, Deschenes et al. [9] concluded that the production of testosterone, which peaks in the morning and declines in early evening, was the cause of changes in tendon stiffness. They proved that there was a significant circadian effect on nerve conduction velocity, sensitivity, and neuromuscular efficiency, which followed fluctuation of core temperature. However, these findings are against the observations by Reilly et al. [4], who reported that circadian rhythm had an insignificant influence on whole body flexibility.

The gains in the hamstring flexibility of the 3 groups may be attributed to the changes in muscular length due to increases in the number of sarcomeres in series [36]. Taylor et al. [37] reported that after stretching, some viscoelastic properties of the muscular connective tissue changed, the resistance tension diminished, and the muscle became more complacent, which may explain the increased hamstring concentric torque as caused by increasing the elastic components of the muscle. Moreover, most of the strength improvement after stretching is due to the passive components, as well as the contractile and active components of the muscles [38]. Also, Worrell et al. [39] attributed these improvements to a greater ability of the stretched muscle to store elastic potential energy absorbed during the eccentric contractions, which exceed the concentric contractions; this would improve the later strength of the concentric contractions. These authors observed that there was a significant increase in the concentric torque after stretching, which coincides with the current results.

The increased hamstring torque may be due to neural factors rather than changes in series elastic component stiffness and flexibility. Yamashita et al. [40] found that stretching a rat soleus muscle by 10 and $20 \%$ increased post-tetanic potentiation of the miniature end-plate potential, which indicates increased $\mathrm{Ca}^{2+}$ conductance in the nerve terminal, facilitating neurotransmitter release. So, the muscle force generation should increase as a result of raised transmitter release. Moreover, De Deyne [41] reported that one of the chronic effects of static stretch was the build-up of sarcomerogenesis. The improvement of hamstring torque and flexibility of the 3 groups can be explained by the findings of Chtourou and Souissi [7], who observed that adaptations to training were greater at the time of day at which training was regularly performed than at other times. Moreover, training in a specific time of day increased the strength over the time course of the day $[9,10]$.

The increased torque in the afternoon and evening groups was significantly higher than that in the morning group. This can be explained by the findings of Martin et al. [10], who examined the effect of time of day $(07: 00 \mathrm{~h}$ vs. 18:00 h) on maximal voluntary contraction (MVC). They reported that the force produced during an MVC was higher at 18:00 $\mathrm{h}$ than at 07:00 h. Likewise, Gauthier et al. [42] investigated the effect of time of day on isometric and isokinetic torque of the elbow flexor muscles at different angular velocities, showing a significant effect of circadian rhythm on muscle isometric and isokinetic torque, with higher values observed between 17:50 $\mathrm{h}$ and 18:30 $\mathrm{h}$.

Additionally, Nicolas et al. [43] observed a significant diurnal variation in muscle strength during 50 MVCs of the knee extensors at the angular velocity of $120 \%$ s, with the peak value observed at 18:00 h. Moreover, Guette et al. [44] found a significant time-of-day effect on MVC torque of the knee extensors for the dominant and non-dominant legs, with highest values occurring at 18:00 h. In the same way, Souissi et al. [8] studied the circadian rhythm of peak power and mean power and reported a significant time-of-day effect, with morning nadirs (ca. 06:00 h), and afternoon or early evening peak values (18:24 $\mathrm{h}$ and 18:00 $\mathrm{h}$ for peak power and mean power, respectively). This may explain the non-significant difference between afternoon and evening groups. Likewise, during intermittent exercise, Chtourou et al. [45] showed that muscle power was significantly higher in the evening $(17: 00 \mathrm{~h})$ compared with the morning $(07: 00 \mathrm{~h})$ only for the first two sprints during a $5 \times 6$-s sprint exercise.

Besides, Sinclair et al. [12] suggested that both male and female athletes should perform knee flexion strengthening exercises training/competitions in the late afternoon or early evening in order to maximize the performance. Furthermore, Pallarés et al. [46] reported that performance was significantly enhanced in the afternoon compared with the morning in 25-m swimming time, bench press maximum strength, bench press muscle power, and jump height, but not in crank arm power. However, the results of hamstring torque of the present study were not consistent with the findings of Souissi et al. [47], who assessed the effect of time-of-day specific training on the diurnal variations of short-term performances in boys. They observed that time-of-day specific training increased the child's anaerobic performance specifically at this time of day. Moreover, the improvement of their physical performance was greater after morning than after evening training.

However, most of the previous studies $[4,7-9,11,12$, $15,29,30,42-46]$ reported that the physical performance was time-dependent, with morning lowest values and afternoon/evening peak values; it is impossible to attribute the inability of the morning group to achieve the same improvement level as the afternoon and evening groups to circadian rhythm. Chtourou et al. [48], in turn, showed that regular morning training reduced the difference between morning and afternoon in the diurnal variation of muscle power and strength. They observed that the subjects of the morning training group improved their performance at 07:00 $\mathrm{h}$ and at 17:00 h, with greater increase at the time of day at which they regularly trained. However, the subjects of the afternoon training group improved their performance only at 17:00 $\mathrm{h}$ and this improvement resulted from a higher difference between morning and afternoon muscle strength and power.

\section{Limitations}

The evaluation of participants was conducted at the same time of day as the static stretch training. So, this study did not examine the effect of training at a specific time of day on hamstring peak torque and flexibility at a different time of day. Cook et al. [49] reported that morning strength training was associated with improved physical performance in the afternoon. So, further research is needed to determine if stretch training in the morning will affect the hamstring strength and flexibility in the evening and afternoon and vice versa. The presented study was conducted among trained male participants. It is therefore recommended to perform such a study among male and female samples in order to allow the findings to be generalized. The static stretch training was applied for one muscle group, which is a rare situation in clinical practice of athletic training. The chronotype of the participants was not assessed before the first testing session. Although 
Karagul et al. [5] found that chronotype did not affect the balance results of subjects with different physical activity levels, it must be considered in future studies. Finally, it is important to note that the concentric and eccentric hamstring torque was measured without consideration of other isokinetic parameters, like isometric torque, power, work, and fatigue.

\section{Conclusions}

The present results displayed that static stretch training of trained individuals, 3 repetitions of $30 \mathrm{~s}, 5$ times/week for 6 weeks, at the same time of day, produced a significant increase in the hamstring eccentric and concentric torque and flexibility. Moreover, static stretching in the afternoon and evening induced more gains in hamstring torque and flexibility than morning stretching. So, static stretching is a time-dependent task that should be considered by clinicians, coaches, and athletes to be scheduled in the afternoon or evening.

\section{Acknowledgement}

We wish to thank all subjects who participated in our study for their patience and invaluable cooperation during the whole experiment.

\section{Disclosure statement}

No author has any financial interest or received any financial benefit from this research.

\section{Conflict of interest}

The authors state no conflict of interest.

\section{References}

1. Meijer JH, Schwartz WJ. In search of the pathways for light-induced pacemaker resetting in the suprachiasmatic nucleus. J Biol Rhythms. 2003;18(3):235-249; doi: 10.1177/0748730403018003006.

2. Zhang X, Dube TJ, Esser KA. Working around the clock: circadian rhythms and skeletal muscle. J Appl Physiol. 2009;107(5):1647-1654; doi: 10.1152/japplphysiol.00725. 2009.

3. Dudek M, Meng QJ. Running on time: the role of circadian clocks in the musculoskeletal system. Biochem J. 2014;463(Pt 1):1-8; doi: 10.1042/BJ20140700.

4. Reilly T, Atkinson G, Edwards B, Waterhouse J, Farrelly K, Fairhurst E. Diurnal variation in temperature, mental and physical performance, and tasks specifically related to football (soccer). Chronobiol Int. 2007;24(3):507-519; doi: 10.1080/07420520701420709.

5. Karagul O, Nalcakan GR, Dogru Y, Tas M. Effects of circadian rhythm on balance performance. Pol J Sport Tourism. 2017;24(3):155-161; doi: 10.1515/pjst-2017-0016.

6. Bessot N, Nicolas A, Moussay S, Gauthier A, Sesboüé $B$, Davenne $D$. The effect of pedal rate and time of day on the time to exhaustion from high intensity exercise. Chronobiol Int. 2006;23(5):1009-1024; doi: 10.1080/ 07420520600920726.

7. Chtourou $\mathrm{H}$, Souissi $\mathrm{N}$. The effect of training at a specific time of day: a review. J Strength Cond Res. 2012;26(7): 1984-2005; doi: 10.1519/JSC.0b013e31825770a7.

8. Souissi N, Gauthier A, Sesboüé B, Larue J, Davenne D. Circadian rhythms in two types of anaerobic cycle leg exercise: force-velocity and 30-s Wingate tests. Inter J SportsMed.2004;25(1):14-19;doi:10.1055/s-2003-45226.
9. Deschenes MR, Kraemer WJ, Bush JA, Doughty TA, Kim D, Mullen KM, et al. Biorhythmic influences on functional capacity of human muscle and physiological responses. Med Sci Sports Exerc. 1998;30(9):1399-1407; 10.1097/00005768-199809000-00008.

10. Martin A, Carpentier A, Guissard N, van Hoecke J, Duchateau J. Effect of time of day on force variation in a human muscle. Muscle Nerve. 1999;22(10):1380-1387; doi: 10.1002/(SICI)1097-4598(199910)22:10<1380::AIDMUS7>3.0.CO;2-U.

11. Pearson SJ, Onambele GNL. Acute changes in kneeextensors torque, fiber pennation, and tendon characteristics. Chronobiol Int. 2005;22(6):1013-1027; doi: 10.1080/07420520500397900.

12. Sinclair J, Wright J, Hurst HT, Taylor PJ, Atkins S. The influence of circadian rhythms on peak isokinetic force of quadriceps and hamstring muscles. Isokinet Exerc Sci. 2013;21(4):279-284; doi: 10.3233/IES-130498.

13. Bowdle RHW, Warren BL, Kim J. Time of day effect on isokinetic peak torque during knee flexion and extension. Isokinet Exerc Sci. 2016;24(4):285-293; doi: 10.3233/ IES-160628.

14. Ammar A, Chtourou H, Souissi N. Effect of time-of-day on biochemical markers in response to physical exercise. J Strength Cond Res. 2017;31(1):272-282; doi: 10.1519/JSC.0000000000001481.

15. Guariglia DA, Pereira LM, Dias JM, Pereira HM, Menacho MO, Silva DA, et al. Time-of-day effect on hip flexibility associated with the modified sit-and-reach test in males. Inter J Sports Med. 2011;32(12):947-952; doi: 10.1055/s-0031-1283182.

16. Teo W, Newton MJ, McGuigan MR. Circadian rhythms in exercise performance: implications for hormonal and muscular adaptation. J Sports Sci Med. 2011;10(4):600606.

17. Miles JW, Grana WA, Egle D, Min KW, Chitwood J. The effect of anabolic steroids on the biomechanical and histological properties of rat tendon. J Bone Joint Surg Am. 1992;74(3):411-422; doi: 10.2106/00004623199274030-00013.

18. O'Sullivan K, Murray E, Sainsbury D. The effect of warmup, static stretching and dynamic stretching on hamstring flexibility in previously injured subjects. BMC Musculoskel Disord. 2009;10(1):37; doi: 10.1186/1471-2474-10-37.

19. Ichihashi $\mathrm{N}$, Umegaki $\mathrm{H}$, Ikezoe $\mathrm{T}$, Nakamura M, Nishishita S, Fujita K, et al. The effects of a 4-week static stretching programme on the individual muscles comprising the hamstrings. J Sports Sci. 2016;34(23):21552159; doi: 10.1080/02640414.2016.1172725.

20. Abdel-Aziem AA, Abdelraouf OR. Effect of hamstring static stretch training on knee flexion concentric torque. Indian J Physiother Occup Ther. 2011;5(3):130-133.

21. Abdel-Aziem AA, Mohammad WS. Plantar-flexor static stretch training effect on eccentric and concentric peak torque - a comparative study of trained versus untrained subjects. J Hum Kinet. 2012;34(1):49-58; doi: 10.2478/ v10078-012-0063-z.

22. Medeiros DM, Lima CS. Influence of chronic stretching on muscle performance: systematic review. Hum Mov Sci. 2017;54:220-229; doi:10.1016/j.humov.2017.05.006.

23. Davis DS, Quinn RO, Whiteman CT, Williams JD, Young CR. Concurrent validity of four clinical tests used to measure hamstring flexibility. J Strength Cond Res. 2008;22(2): 583-588; doi: 10.1519/JSC.0b013e31816359f2.

24. Milanese S, Gordon S, Buettner P, Flavell C, Ruston S, Coe D, et al. Reliability and concurrent validity of knee 
angle measurement: smart phone app versus universal goniometer used by experienced and novice clinicians. Man Ther. 2014;19(6):569-574; doi: 10.1016/j.math.2014. 05.009.

25. Santos HH, Avila MA, Hanashiro DN, Camargo PR, Salvini TF. The effects of knee extensor eccentric training on functional tests in healthy subjects. Rev Bras Fisioter. 2010;14(4):276-283; doi: 10.1590/S1413-3555201000 5000014.

26. Dvir Z. Isokinetics: muscle testing, interpretation and clinical applications, $2^{\text {nd }}$ ed. New York: Churchill Livingstone; 2004.

27. Decoster LC, Scanlon RL, Horn KD, Cleland J. Standing and supine hamstring stretching are equally effective. J Athl Train. 2004;39(4):330-334.

28. Hill DW, Leiferman JA, Lynch NA, Dangelmaier BS, Burt SE. Temporal specificity in adaptations to high-intensity exercise training. Med Sci Sports Exerc. 1998; 30(3):450-455; doi: 10.1097/00005768-199803000-00017.

29. Martin L, Thompson K. Reproducibility of diurnal variation in sub-maximal swimming. Inter J Sports Med. 2000;21(6): 387-392; doi: 10.1055/s-2000-3829.

30. Edwards BJ, Edwards W, Waterhouse J, Atkinson G, Reilly T. Can cycling performance in an early morning, laboratory-based cycle time-trial be improved by morning exercise the day before? Inter J Sports Med. 2005;26(08): 651-656; doi: 10.1055/s-2004-830439.

31. West DJ, Cook CJ, Beaven MC, Kilduff LP. The influence of the time of day on core temperature and lower body power output in elite rugby union sevens players. J Strength Cond Res. 2014;28(6):1524-1528; doi: 10.1519/JSC. 0000000000000301.

32. Bandy WD, Irion JM. The effect of time on static stretch on the flexibility of the hamstring muscles. Phys Ther. 1994;74(9):845-850; doi: 10.1093/ptj/74.9.845.

33. Cini A, de Vasconcelos GS, Lima CS. Acute effect of different time periods of passive static stretching on the hamstring flexibility. J Back Musculoskelet Rehabil. 2017; 30(2):241-246; doi: 10.3233/BMR-160740.

34. Berenbaum K, Bui B, Megaro S, Whidden MA. Static and dynamic stretching and its effects on hamstring flexibility, horizontal jump, vertical jump, and a 50 meter sprint. J Sport Hum Perf. 2015;3(4):1-12; doi: 10.12922/jshp. v3i4.65.

35. Gifford LS. Circadian variation in human flexibility and grip strength. Aust J Physiother. 1987;33(1):3-9; doi: 10.1016/S0004-9514(14)60579-1.

36. Williams PE, Goldspink G. Changes in sarcomere length and physiological properties in immobilized muscle. $J$ Anat. 1978;127(Pt 3):459-468.

37. Taylor CD, Brooks DE, Ryan JB. Viscoelastic characteristics of muscle: passive stretching versus muscular contractions. Med Sci Sports Exerc. 1997;29(12):16191624; doi: 10.1097/00005768-199712000-00011.

38. Herzog W, Leonard TR. Force enhancement following stretching of skeletal muscle: a new mechanism. J Exp Biol. 2002;205(Pt 9):1275-1283.

39. Worrell TW, Smith TL, Winegardner J. Effect of hamstring stretching on hamstring muscle performance. J Orthop Sports Phys Ther. 1994;20(3):154-159; doi: 10.2519/jospt.1994.20.3.154.

40. Yamashita T, Ishii S, Oota I. Effect of muscle stretching on the activity of neuromuscular transmission. Med Sci Sports Exerc. 1992;24(1):80-84.

41. De Deyne PG. Application of passive stretch and its
819-827; doi: 10.1093/ptj/81.2.819.

42. Gauthier A, Davenne D, Martin A, Van Hoecke J. Time of day effects on isometric and isokinetic torque developed during elbow flexion in humans. Eur J Appl Physiol. 2001;84(3):249-252; doi: 10.1007/s004210170014.

43. Nicolas A, Gauthier A, Bessot N, Moussay S, Davenne D. Time-of-day effects on myoelectric and mechanical properties of muscle during maximal and prolonged isokinetic exercise. Chronobiol Int. 2005;22(6):997-1011; doi: 10.1080/07420520500397892.

44. Guette M, Gondin J, Martin A. Time-of-day effect on the torque and neuromuscular properties of dominant and non-dominant quadriceps femoris. Chronobiol Int. 2005; 22(3):541-558; doi: 10.1081/CBI-200062407.

45. Chtourou H, Hammouda O, Souissi H, Chamari K, Chaouachi A, Souissi N. Diurnal variations in physical performances related to football in young soccer players. Asian J Sports Med. 2012;3(3):139-144; doi: 10.5812/ asjsm.34604.

46. Pallarés JG, López-Samanes Á, Moreno J, FernándezElías VE, Ortega JF, Mora-Rodríguez R. Circadian rhythm effects on neuromuscular and sprint swimming performance. Biol Rhythm Res. 2014;45(1):51-60; doi: 10.1080/09291016.2013.797160.

47. Souissi H, Chtourou H, Chaouachi A, Dogui M, Chamari K, Souissi N, et al. The effect of training at a specific timeof-day on the diurnal variations of short-term exercise performances in 10- to 11-year-old boys. Pediatr Exerc Sci. 2012;24(1):84-99; doi: 10.1123/pes.24.1.84.

48. Chtourou H, Driss T, Souissi S, Gam A, Chaouachi A, Souissi $N$. The effect of strength training at the same time of the day on the diurnal fluctuations of muscular anaerobic performances. J Strength Cond Res. 2012; 26(1):217-225; doi: 10.1519/JSC.0b013e31821d5e8d.

49. Cook CJ, Kilduff LP, Crewther BT, Beaven M, West DJ. Morning based strength training improves afternoon physical performance in rugby union players. J Sci Med Sport. 2014;17(3):317-321; doi: 10.1016/j.jsams.2013.04.016. 